\title{
Assessments on the Performance of Asphalt Mixtures Prepared with Adhesion Promoters
}

\author{
Nge Jia Sheng, Mohd Rosli Mohd Hasan, Sharvin Poovaneshvaran, Ramadhansyah Putra Jaya, \\ Ali Huddin Ibrahim
}

\begin{abstract}
Asphalt pavement is typically susceptible to moisture damage. However, it could be improved with the incorporation of additives or modifiers through binder modifications. The objective of the study is to assess the effect of adhesion promoters, namely PBL and M5000, onto the Hot Mix Asphalt (HMA). The performance of asphalt mixture has been assessed in terms of the service characteristics, the bonding properties, and mechanical performances. The service characteristics were assessed through the Workability Index (WI) and Compaction Energy Index (CEI) to evaluate the ease of asphalt mixture during the mixing and compaction stage. The bonding properties of the modified asphalt mixtures were determined using the boiling water test and static water immersion test to signify the degree of coating after undergoing specific conditioning period and temperature. The mechanical performances of the modified asphalt mixture were evaluated via Marshall stability, semi-circular bending, and modified Lottman tests. All specimens were prepared by incorporating adhesion promoters at the dosage rates of $0.5 \%$ and $1.0 \%$ by weight of asphalt binder. From the investigation, the bonding properties significantly improved for the modified asphalt mixture compared to the control mixture. The WI of the modified asphalt mixture increased while the CEI decreased in comparison to the control specimen. This implies the workability of modified asphalt mixture is better and requires less energy to be compacted. Modified asphalt mixture generally had better mechanical performance. Therefore, it can be deduced that the asphalt mixture with adhesion promoters have better overall performance than the control mixture.
\end{abstract}

Keywords: adhesion promoters, binder modifications, mechanical performance, service characteristics

\section{INTRODUCTION}

Hot Mix Asphalt (HMA) is the most common type of asphalt pavement constructed in Malaysia. HMA is defined as

Revised Manuscript Received on October 22, 2019.

* Correspondence Author

Nge Jia Sheng, School of Civil Engineering, Engineering Campus, Universiti Sains Malaysia, Penang, Malaysia. Email: jsheng_nge95@hotmail.com

Mohd Rosli Mohd Hasan*, School of Civil Engineering, Engineering Campus, Universiti Sains Malaysia, Penang, Malaysia. Email: cerosli@usm.my

Sharvin Poovaneshvaran, School of Civil Engineering, Engineering Campus, Universiti Sains Malaysia, Penang, Malaysia. Email: sharvinpoovaneshvaran@gmail.com

Ramadhansyah Putra Jaya, Faculty of Civil Engineering Technology, Universiti Malaysia Pahang, Gambang, Pahang, Malaysia. Email: ramadhansyah@ump.edu.my

Ali Huddin Ibrahim, currently appointed as a research officer at the School of Civil Engineering, Universiti Sains Malaysia. He is an active researcher on wide ranges of research area related to the Civil and Environmental Engineering. Email: ceali@usm.my a complex mixture composed of asphalt binders, aggregates, and mineral fillers. The asphalt binder act as an adhesive material, binding the aggregate into a dense mass and waterproofing the aggregate particles. The mineral aggregate, when bound together, act as a stone framework to provide strength and toughness to the composite system.

However, typical asphalt pavement roads are less durable and highly susceptible to harsh climate, particularly rainy weather. Moisture damage is a prevalent failure of bonding in asphalt pavement. This remain as a topic of debate among researchers for years [1]. Moisture damage is defined as the loss of strength, bonding, and stability caused by the presence of moisture in asphalt pavement [2]. Whereas, Behiry [3] stated that the moisture damage usually causes the loss of bonding between asphalt-aggregate interface and also the reduction of bonding within the asphalt binder itself. Sebaaly et al. [4] mentioned that this phenomena could lead to various types of pavement distresses such as raveling, stripping, cracking, rutting, and potholes.

The propagation of moisture damage generally occurs through two mechanisms: the loss of adhesion and cohesion [5]. Adhesion is the bonding mechanism between the aggregate particles and the asphalt binder. While, cohesion is the bonding mechanism that present within the molecules of asphalt binder itself. The adhesion and cohesion between the asphalt binder and aggregates are the forces that are holding the asphalt mixtures together. According to Lytton et al. [6], asphalt film thickness, aggregate shape characteristics, and surface energy are the contributing factors that affect the resistance towards moisture damage. Abuawad et al. [7] specified that the most common technique to mitigate moisture damage is by using additives or modifiers during the production of asphalt mixture. Various additives and modifiers are used to enhance the performance of asphalt mixtures. The purpose of the study is to assess the performance of the asphalt mixtures incorporating adhesion promoters in terms of service characteristics, bonding properties and its mechanical performance. A variety of tests including boiling water test, static test method, Marshall stability, semi-circular bending test and Modified Lottman test were conducted and compared with the control mix. 


\section{EXPERIMENTAL MATERIALS}

\section{A. Aggregates}

Crushed granite aggregates with various sizes were used throughout this study to prepare the asphalt mixture samples.

The aggregate gradation adopted in this study was based on the Malaysian Public Works Department (PWD) AC14 wearing course, as specified in Table-I.

Table- I: Design of PWD Asphaltic Concrete 14

\begin{tabular}{|c|c|c|c|}
\hline B.S Sieve Size & $\begin{array}{c}\text { \% Passing } \\
\text { (By Weight) }\end{array}$ & $\begin{array}{c}\text { Median } \\
(\boldsymbol{\%})\end{array}$ & $\begin{array}{c}\text { AC 14 Mix } \\
\text { Design (\%) }\end{array}$ \\
\hline $20 \mathrm{~mm}$ & 100 & 100 & 0 \\
\hline $14 \mathrm{~mm}$ & $90-100$ & 95 & 5 \\
\hline $10 \mathrm{~mm}$ & $76-86$ & 81 & 14 \\
\hline $5 \mathrm{~mm}$ & $50-62$ & 56 & 25 \\
\hline $3.35 \mathrm{~mm}$ & $40-54$ & 47 & 9 \\
\hline $1.18 \mathrm{~mm}$ & $18-34$ & 26 & 21 \\
\hline $425 \mu \mathrm{m}$ & $12-24$ & 18 & 8 \\
\hline $150 \mu \mathrm{m}$ & $6-14$ & 10 & 8 \\
\hline $75 \mu \mathrm{m}$ & $4-8$ & 6 & 4 \\
\hline Mineral & - & - & 4 \\
\hline Filler & & & 2 \\
\hline OPC & - & - & \\
\hline
\end{tabular}

\section{B. Asphalt Binder}

Bitumen is regarded as the binding agent that holds the aggregate particles together in the asphalt mixture. In general, the binder generally comprise of $4-8 \%$ of the asphalt mixture by weight [8]. Conventional asphalt binder with the penetration grade of 60/70 was used. An optimum binder content of $5.0 \%$ by weight of aggregates was adopted for the production of asphalt mixture.

\section{Adhesion Promoters}

Two liquid adhesion promoters, named Pave Bond Lite (PBL) and Morlife 5000 (M5000), were used. The adhesion promoters were added at two different dosage of $0.5 \%$ and $1.0 \%$ by the weight of asphalt binder. The physical and chemical components of the adhesion promoters are as shown in Table-II.

Table- II: Physical and Chemical Components of PBL

\begin{tabular}{|c|c|c|}
\hline Properties & PBL & M5000 \\
\hline Ingredients & $\begin{array}{c}\text { Polyalkylene Glycol } \\
\text { Mixture \& Glycol } \\
\text { Ethers }\end{array}$ & $\begin{array}{c}\text { Polyethylene } \\
\text { polyamines }\end{array}$ \\
\hline Physical Form & Dark Brown Liquid & Dark Brown Liquid \\
\hline Odor & Ammoniacal & Fishy \\
\hline $\begin{array}{c}\text { Specific } \\
\text { Gravity }\end{array}$ & 1.04 & 1.09 \\
\hline Boiling Point & $>220^{\circ} \mathrm{C}$ & $255^{\circ} \mathrm{C}$ \\
\hline Flashpoint & $155^{\circ} \mathrm{C}$ & $145^{\circ} \mathrm{C}$ \\
\hline
\end{tabular}

\section{Preparation of PBL and M5000-Modified Binder}

Prior to the preparation of the modified asphalt binder, the base asphalt binder was pre-heated for 2 hours at $160^{\circ} \mathrm{C}$. The required dosage rates of $0.5 \%$ and $1.0 \%$ were added into the and M5000

pre-heated asphalt binder. The asphalt binder was then blended using a high shear mixer at $160^{\circ} \mathrm{C}$ for 30 minutes with the speed of $1000 \mathrm{rpm}$ to ensure the homogeneity of the asphalt binder.

\section{TEST PROCEDURES}

\section{A. Compaction Energy Index (CEI)}

The compactability of asphalt mixture was assessed while compacting the specimen using Servopac Gyratory Compactor (SGC). The energy needed to compact the asphalt mixtures to the desired density is represented by CEI. The mixtures with lower CEI values represent that less energy is required for the compaction process to achieve the desired density. CEI was computed by the integral of the area under the densification curve (degree of compaction against numbers of gyration) between the 8th gyration and $92 \% \mathrm{G}_{\mathrm{mm}}$ [9]. Equation (1) was used to fit the data collected from the SGC:

$$
\mathrm{A}_{\mathrm{A}}=\mathrm{aNi}-\mathrm{b}
$$

Where $\mathrm{A}_{\mathrm{A}}=$ Accumulated area;

$$
\mathrm{a} \text {, and } \mathrm{b}=\text { regression coefficients }
$$

\section{B. Workability Index (WI)}

Workability represents the ease of asphalt mixture blending at the specified temperature. Dessouky and Diaz [10] stated that the asphalt mixture resistance to compaction which are expressed in terms of specimens height reduction versus the number of gyrations, can be used to evaluate the workability and compactability of the asphalt mixture. Mohd Hasan et al. [9] derived the workability index (WI) by plotting the semi-logarithmic relationship between air voids and the number of gyrations. The reduction of air void is linearly linked to the number of gyrations with a correlation coefficient of more than $90 \%$. Asphalt mixture that exhibits higher WI represent that the asphalt mixture is more workable and shall require less energy to be compacted. The regression shows a negative linear relationship as Equation (2).

$$
\mathrm{AV}(\%)=-\mathrm{aN} i+\mathrm{b}
$$

Where $\mathrm{AV}=$ air void; $\mathrm{a}$ and $\mathrm{b}$ are regression coefficients; and WI is computed using Equation (3).

$$
\mathrm{WI}=100 / \mathrm{b}
$$

\section{Boiling Water Test}

Boiling water test is a method to evaluate the loss of adhesion in loose asphalt mixture due to the action of boiling water. This test was carried out in accordance with ASTM D3625 [11]. During test, $250 \mathrm{~g}$ of loose asphalt mixture comprise of coarse and fine aggregates was prepared. Before placing the sample into the boiling water, the temperature of the loose asphalt mixtures was kept below the water boiling temperature but not less than $85^{\circ} \mathrm{C}$. The loose asphalt mixture was then immersed in boiling water $\left(100^{\circ} \mathrm{C}\right)$ for 10 minutes \pm $15 \mathrm{sec}$. Excessive manipulation of the loose asphalt mixture should be avoided. At the end of 10 minutes, any asphalt binder that are floating on the water surface was skimmed off to avoid recoating. 
Then, the wet mixture was transferred to a white towel and allowed to cool under room temperature. The visual rating was conducted to assess the level of stripping after the sample had cooled down.

\section{Static Water Immersion Test}

Static water immersion test was carried out to determine the percentage of asphalt binder that remain coated after being immersed in water. This test was conducted according to BS EN 12697-11 [12]. Approximately, 150g of aggregates with size of $10 / 14 \mathrm{~mm}$ were prepared and mixed with asphalt binder. After an hour of cooling down the loose asphalt mixture, the sample was then immersed in water at $40 \pm 1{ }^{\circ} \mathrm{C}$ for 48 hours. If the adhesion strength between aggregates and asphalt binder are weak, it would result in partial removal of coated film due to the infiltration of water between the thin asphalt binder film. The degree of coating for each mineral aggregate were visually assessed.

\section{E. Marshall Stability}

Marshall stability test was conducted to determine the stability and flow of the asphalt mixture. The test was carried out in reference to ASTM D6927-06 [13]. Stability is the maximum load attained by the asphalt mixture prior to the failure. While, flow is the deformation of asphalt mixture at the point of failure. The compacted specimens were conditioned in the water bath for 30 to 40 minutes at $60 \pm 1^{\circ} \mathrm{C}$. The load was applied to the specimen at the constant rate of $50 \pm 5 \mathrm{~mm} / \mathrm{min}$.

\section{F. Semi-Circular Bending Test}

The Semi-Circular Bending Test (SCB) was carried out in accordance to AASHTO TP 124. SCB was conducted to determine the maximum tensile strength of asphalt mixture [14]. A specimen with diameter of $150 \mathrm{~mm}$ and thickness of $50 \mathrm{~mm}$ was cut into two identical semi-circular sample. A notch of approximately $15 \pm 0.5 \mathrm{~mm}$ in length along the axis of symmetry of each semi-circular was cut. The specimens were conditioned in an incubator at $15^{\circ} \mathrm{C}$ for 4 hours before testing. SCB test is a simple three-point bending configuration. Two roller supports were separated at $2 \mathrm{~s}=120$ $\pm 0.1 \mathrm{~mm}$ apart. The specimen was subjected to a load cell of $100 \mathrm{kN}$ with a constant displacement rate of $50.8 \mathrm{~mm} / \mathrm{min}$. Somé et al. [15] demonstrated that the maximum tensile at failure, omax is given by Equation (4).

$\sigma_{\max }=4.263 \mathrm{~F}_{\max } / \mathrm{Dt}$

Where

$\mathrm{F}_{\max }=$ Maximum load at failure $(\mathrm{N})$;

$\mathrm{D}=$ Specimen diameter $(\mathrm{mm})$

$\mathrm{t}=$ Specimen thickness $(\mathrm{mm})$

\section{G. Modified Lottman Test}

Modified Lottman test was conducted to evaluate the resistance of compacted asphalt mixtures to moisture induced damage. The test was carried out according to AASHTO T283 [16]. Two sets of compacted specimens with diameter of $100 \mathrm{~mm}$ and height of $63.5 \pm 2.5 \mathrm{~mm}$ were prepared. Three specimens were prepared for each set. After the mixing process, the loose asphalt mixture was cooled at room temperature for $2 \pm 0.5$ hours. Then, the loose asphalt mixture was cured in an oven for $16 \pm 1$ hours at $60 \pm 3^{\circ} \mathrm{C}$. After the curing duration, the loose asphalt mixture was heated at the compaction temperature of $150^{\circ} \mathrm{C}$ for 2 hours \pm 10 minutes prior to compaction. The specimens were compacted with suitable number of gyration in order to achieve air voids of $7.0 \pm 0.5 \%$. The specimens were then left to cool down under room temperature before conducting the test. The specimens were separated into two subsets, namely dry (unconditioned) and wet (conditioned). The subset tested dry was wrapped with a heavy-duty plastic bag and placed in an incubator at $15^{\circ} \mathrm{C}$ for 2 hours \pm 10 minutes.

The wet subset was tested by applying a vacuum of $13-67$ $\mathrm{kPa}$ absolute pressure for about 5 to 10 minutes in a container filled with potable water at room temperature. Then, the specimen was left submerged in water for about 5 to 10 minutes. The vacuumed specimens should reach a degree of saturation between $70 \%$ and $80 \%$. The vacuum-saturated specimens were then wrapped tightly using a plastic bag containing $10 \pm 0.5 \mathrm{ml}$ of water. The wrapped specimens were then placed in a freezer at the temperature of $-18 \pm 3^{\circ} \mathrm{C}$ for a minimum of 16 hours.After the freezing process, the specimens were then exposed to thawing process where the specimens were put into a water bath at $60 \pm 1^{\circ} \mathrm{C}$ for 24 hours \pm 1 hour. After the thawing process, the specimens were conditioned in an incubator at $15^{\circ} \mathrm{C}$ for 2 hours \pm 10 minutes.

The specimen of dry and wet conditioned were then subjected to a constant loading rate of $50.8 \mathrm{~mm} /$ minute at $15^{\circ} \mathrm{C}$ along its diametrical axis. The indirect tensile strength (ITS) of dry and wet conditioned specimen was calculated using Equation (5).

Indirect tensile strength, ITS $(\mathrm{kPa})=2000 \mathrm{P} / \pi \mathrm{hD}$ Where

$\mathrm{P}=$ maximum load applied to the specimen $(\mathrm{N})$

$\mathrm{h}=$ Specimen height immediately before test $(\mathrm{mm})$

$\mathrm{D}=$ Specimen diameter $(\mathrm{mm})$

Moisture susceptibility determined by the indirect tensile strength ratio (ITSR) using Equation (6).

ITSR $=$ ITS (Conditioned)/ ITS (Dry)

\section{RESULTS AND DISCUSSION}

\section{A. Compaction Energy Index (CEI)}

Fig. 1 shows the computed CEI of the asphalt mixtures incorporating adhesion promoters. It shows that the unmodified asphalt mixture has the highest CEI, which is 51.03 in relative to modified asphalt mixtures. The CEI of the $\mathrm{P} 0.5 \%$ and the $\mathrm{P} 1.0 \%$ are 38.28 and 25.74 , respectively. The same trend has also been observed for $\mathrm{M} 0.5 \%$ and $\mathrm{M} 1.0 \%$. As the dosage rate increased from $0.5 \%$ to $1.0 \%$, the CEI decreases from 46.87 to 34.52 , accordingly. With the presence of adhesion promoters, a significant reduction in CEI is observed compared to the control mixture. 


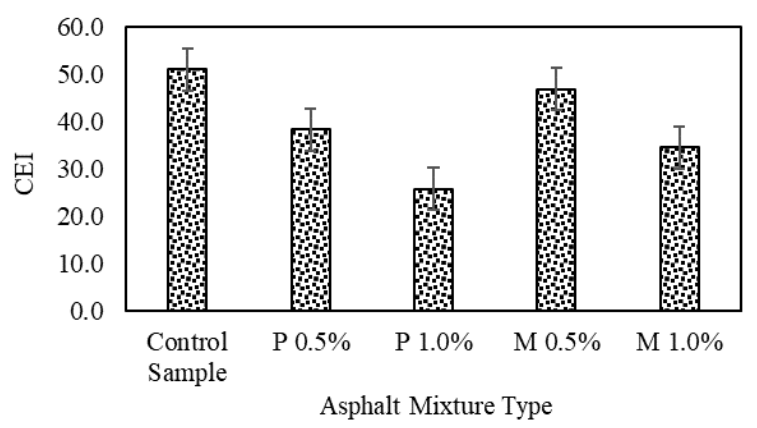

Fig. 1. Compaction Energy Index

Lower CEI is desirable as it represents that less energy is required to compact the asphalt mixture to the required density. However, very low CEI should be prevented as this could be a sign of a tender mixture. Besides, CEI is also inversely proportional to WI. The lower the workability of the asphalt mixture, the higher the energy required for compaction of asphalt mixture.

\section{B. Workability Index (WI)}

From the graph of the workability index shown in Fig. 2, it can be concluded that the control sample has the lowest WI of 4.081 compared to other mixture type. The modified asphalt mixtures with P $0.5 \%$ and P $1.0 \%$ have the WI of 4.208 and 4.366 respectively. Whereas asphalt mixtures prepared with M $0.5 \%$ and M $1.0 \%$ achieve the WI of 4.277 and 4.343, respectively. Overall, the incorporation of both adhesion promoter at different percentages has similarly comparable outcomes in terms of WI.

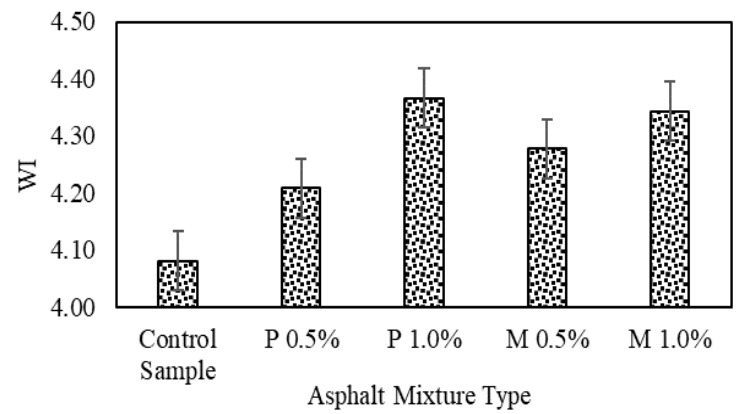

Fig. 2. Workability Index

As shown in Fig. 2, the presence of the PBL and M5000 increases the WI of the asphalt mixture in comparison to the unmodified asphalt mixture. According to the similar research done by Zhu et al. [17], it is reported that with increasing dosage of M5000, the viscosity of the asphalt binder increased initially and then decreased considerably. The viscosity reached a maximum value at the dosage of $0.25 \%$. Since the dosage rates used for both adhesion promoters are $0.5 \%$ and $1.0 \%$, therefore, the viscosity would be lower, which subsequently would improve the workability index as obtained in this study. In conclusion, the asphalt mixtures incorporating adhesion promoters at higher percentages are easier to be mixed, coated, and compacted to the required specifications.

\section{Boiling Water Test}

According to the boiling water test result, it can be inferred that the use of adhesion promoters can improve the adhesion between the asphalt binder and the aggregate. The usage of adhesion promoters enhanced the durability of the asphalt mixture against moisture damage. Therefore, all the modified asphalt mixtures demonstrated superior adhesion even after subjecting to the action of boiling water. The modified loose asphalt mixture retained approximately $100 \%$ degree of coating at the end of the test. Whereas, the control sample demonstrated the lowest degree of asphalt binder coverage. According to the visual observation, the control sample only retained approximately $80 \%$ of asphalt binder coating.

The strong difference of the asphalt binder coverage between the control sample and the modified asphalt mixture can be appreciated from Fig. 3. The degree of asphalt binder coverage after the test is estimated and classified as above $95 \%$ or below $95 \%$. The findings shows that the control sample retained $<95 \%$ of the initial coating. While all the modified asphalt mixtures irrespective of adhesion promoters retained $>95 \%$ of the initial coating. The results appear to be in line with earlier research conducted by Liu et al. [18] as the use of the adhesion promoters caused a measurable decrease in binder loss and is effective in reducing moisture sensitivity.

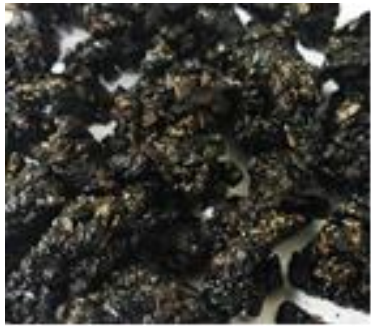

(a)

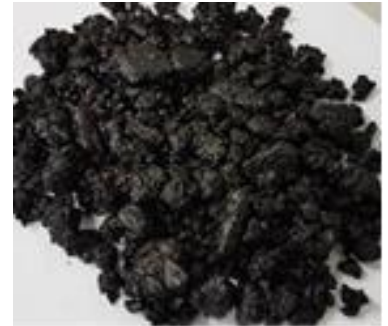

(b)
Fig. 3. Captured Image After Boiling Test (a) Control (b) P 0.5\% HMA

\section{Static Water Immersion Test}

From Fig. 4, it can be seen that after 48 hours of water conditioning, the control sample has the lowest percentage of aggregate remains fully-coated, which is $51 \%$ compared to the modified asphalt mixtures. While all modified asphalt mixtures incorporating PBL and M5000 regardless of the dosage rates, demonstrated a good affinity with asphalt binder, where $100 \%$ of aggregate remaining coated. Since there is no any significant asphalt binder debonding detected from the aggregate of the modified asphalt mixtures, thus it is impossible to differentiate and compare the influence of different adhesion promoters at different dosages on the degree of coating.

The percentage of aggregate remain coated on the control, and the modified asphalt mixture after subjecting to static water conditioning is as illustrated in Fig. 5. From Fig. 5, it is clear that the control sample suffers from moisture damage, and the degree of particle remain coated is low compared to all types of modified asphalt mixture. 


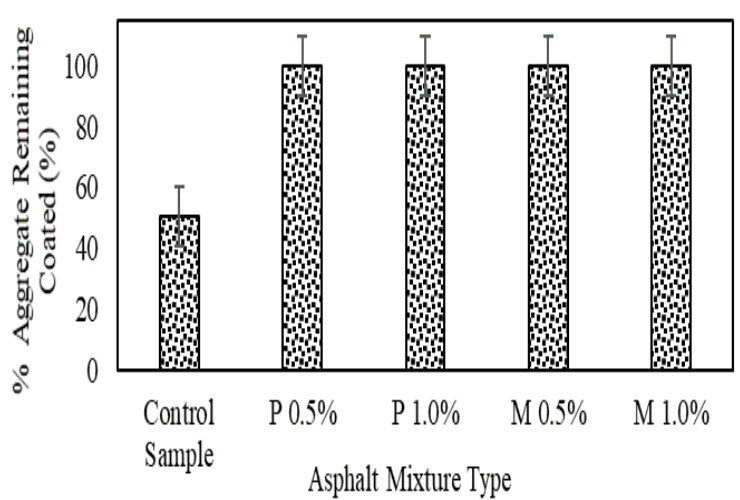

Fig. 4. Percent Aggregate Remaining Intact Coating After Static Test

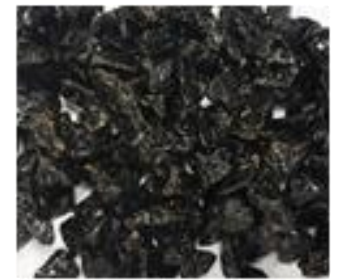

(a)

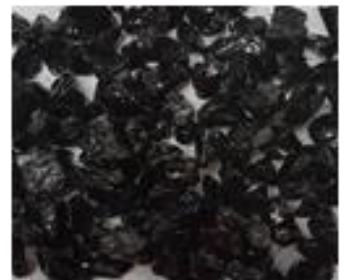

(b)
Fig. 5. Captured Images After Static Method Test (a) Control (b) M 0.5\% HMA

\section{E. Marshall Stability}

Fig. 6 depict the stiffness of all asphalt mixture types. The stiffness of asphalt mixture is computed by dividing the maximum load $(\mathrm{N})$ carried by the specimen over the deformation $(\mathrm{mm})$ during the marshall stability test. The control sample exhibited the lowest stiffness, which is 3493 $\mathrm{N} / \mathrm{mm}$, in comparison to the modified asphalt mixtures. The modified asphalt mixture incorporating $\mathrm{P} 0.5 \%$ has a stiffness of $3530 \mathrm{~N} / \mathrm{mm}$, whereas the $\mathrm{P} 1.0 \%$ asphalt mixture achieved stiffness of $3650 \mathrm{~N} / \mathrm{mm}$. Both the P $0.5 \%$ and the P $1.0 \%$ manifested higher stiffness than the control sample. While the asphalt mixtures incorporating $\mathrm{M} 0.5 \%$ and $\mathrm{M} 1.0 \%$ achieved stiffness values of $3592 \mathrm{~N} / \mathrm{mm}$ and $3693 \mathrm{~N} / \mathrm{mm}$, respectively. From the results, it is evident that both the $\mathrm{M} 0.5 \%$ and the $\mathrm{M}$ $1.0 \%$ have higher stiffness in relative to $\mathrm{P} 0.5 \%$ and $\mathrm{P} 1.0 \%$, respectively. In other words, modified asphalt mixtures exhibits higher stiffness.

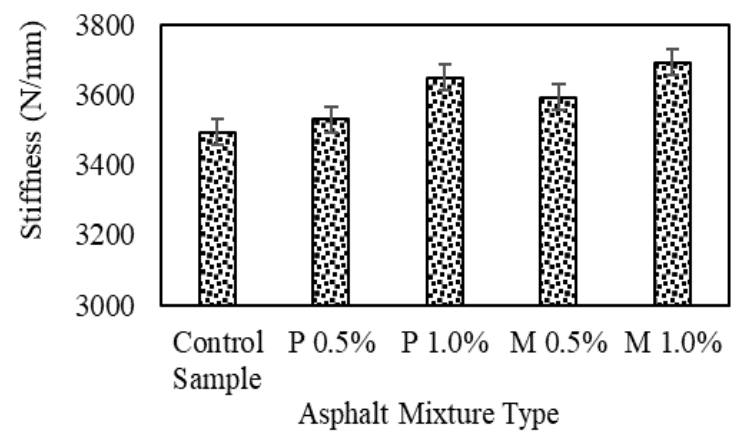

Fig. 6. Marshall Stability of Asphalt Mixtures

Kok et al. [19] stated that the damage in asphalt mixtures might occur within the binder mastic itself (cohesive fracture) or at the interface of the aggregate and binders (adhesive fracture). For the Marshall stability test, adhesive bond strength can be deemed to control the failure mechanism. When the adhesive bond strength increases, the stability values of asphalt mixtures increases as well. This statement is validated by the results shown in Figure 6. It is clearly proven that when the dosage rate of adhesion promoter increases, the stiffness of the asphalt mixture increases too. This shows that the strength gained by the asphalt mixture is greater than the rate of deformation when the dosage rate of adhesion promoters is higher. This subsequently results in higher stiffness of modified asphalt mixture.

\section{F. Semi-Circular Bending Test}

From the results shown in Fig. 7, the control sample has the lowest tensile strength, which is $3.68 \mathrm{MPa}$. The asphalt mixtures incorporating $\mathrm{P} 0.5 \%$ and $\mathrm{P} 1.0 \%$ attained tensile strength of $4.12 \mathrm{MPa}$ and $4.28 \mathrm{MPa}$, respectively. While the asphalt mixtures incorporating $\mathrm{M} 0.5 \%$ and M $1.0 \%$ obtained tensile strength of $3.76 \mathrm{MPa}$ and $4.59 \mathrm{MPa}$, respectively. A similar trend has been observed in the SCB test where asphalt mixtures with the incorporation of PBL and M5000 demonstrated higher resistance against fracture compared to the control sample. This is possible due to the addition of adhesion promoters in asphalt mixture which could substantially enhance the adhesive strength of asphalt mixture.

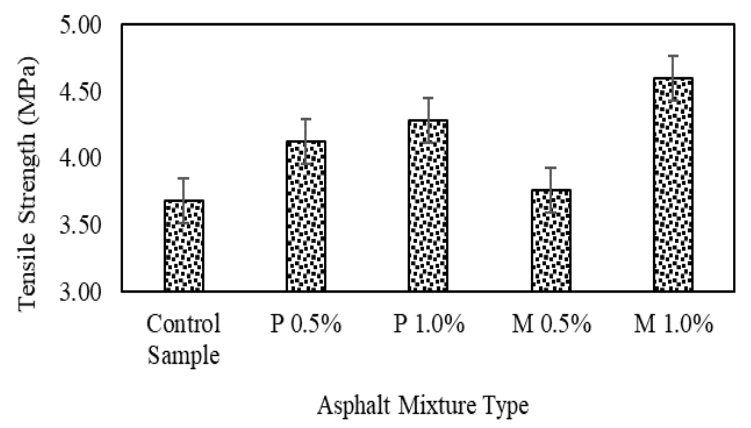

Fig. 7. Tensile Strength of Asphalt Mixtures

The outcome reveals that the modified asphalt mixture performs better than the control mix in terms of the tensile strength, which signifies the adhesion promoters do have impact towards the performance of asphalt mixture. This shows that the result is in line with the study conducted by Al-Qadi et al., where the improvement in terms of fracture resistance of the asphalt mixture is seen when liquid anti-strip (adhesion promoter), styrene-butadiene-styrene (SBS), hydrated lime wet, and hydrated lime marination were used [2].

\section{G. Modified Lottman Test}

The results from the moisture sensitivity test can be used to predict the potential of long-term stripping and to assess the additives added to the asphalt mixture. 
Fig. 8 illustrates the Indirect Tensile Strength (ITS) of different asphalt mixture types under different condition. From Fig. 8, it can be inferred that the control sample has the lowest ITS value among the wet specimen, which is $1697 \mathrm{kPa}$, while the P $1.0 \%$ has the lowest ITS value among the dry specimen, which is $1957 \mathrm{kPa}$. The ITS value of $\mathrm{P} 1.0 \%$ is slightly lower than the control sample in dry condition. Conversely, M 1.0\% has the highest ITS value for both wet and dry condition which are $2060 \mathrm{kPa}$ and $2205 \mathrm{kPa}$, respectively. The conditioned (wet) specimens is reported to have a lower ITS value compared to the unconditioned (dry) specimens because the conditioned (wet) specimens had undergone freeze-thaw cycle in which water causes damage to the asphalt-aggregate interface. Freeze-thaw cycle simulates the effects of moisture damage that occurrs to the asphalt mixture at the actual pavement site, which causes the reduction in adhesive and cohesive strength of asphalt mixture.

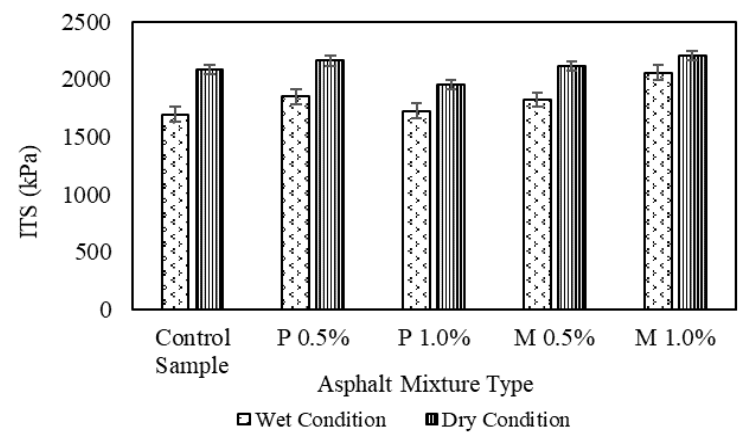

Fig. 8. ITS Value of Conditioned (Wet) and Unconditioned (Dry) Asphalt Mixture

Nazirizad et al. [22] mentioned in the study that it is apparent that the role of adhesion promoters in enhancing the resistance of asphalt mixture against moisture susceptibility and creating a strong asphalt-aggregate bonding. The addition of adhesion promoters could improve the moisture sensitivity of asphalt mixture even under freeze-thaw cycle as proven in this study.

The ITS ratio (ITSR) of asphalt mixture is illustrated in Fig. 9. ITSR act as a performance indicator for moisture sensitivity of asphalt mixtures. From the findings, it is evident that the control specimen has the lowest ITSR among all the asphalt mixture types, which is 0.81 . This shows that the control sample are prone to moisture damage. However, increasing trend in ITSR value had been observed with the incorporation of higher dosage of adhesion promoters irrespective of adhesion promoter type. The ITSR of P $0.5 \%$ and $\mathrm{P} 1.0 \%$ are 0.86 and 0.88 , respectively. Whereas the ITSR of M $0.5 \%$ and M $1.0 \%$ are 0.86 and 0.93 , respectively. Thus, it can be deduced that the M5000 offers better resistance against moisture damage and stripping than the PBL as it has the highest ITSR. Nevertheless, the PBL modified asphalt mixture still has better moisture damage resistance compared to the control sample.

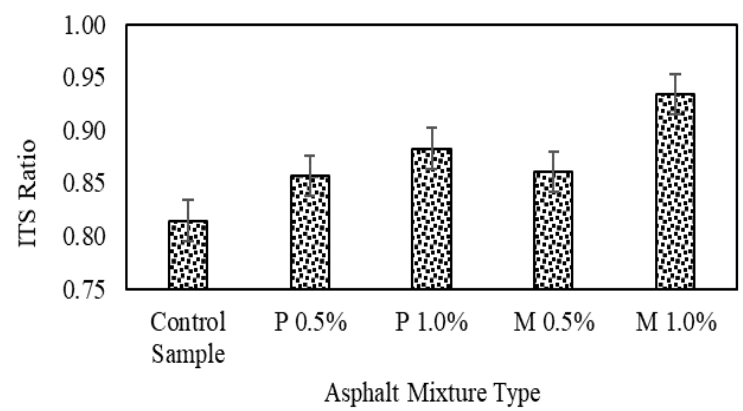

Fig. 9. Indirect Tensile Strength Ratio (ITSR)

\section{CONCLUSION}

The investigation on the effects of adhesion promoters on the asphalt mixtures were evaluated based on CEI, WI, boiling water test, static water immersion test, Marshall stability, semi-circular bending test, and Modified Lottman test. From the result analysis, the following conclusions can be drawn:

- Modified asphalt mixtures incorporating adhesion promoters have higher WI than the control mixture. While the modified asphalt mixtures also exhibits lower CEI than the control specimen. This represents that the modified asphalt mixtures are more workable and require less energy to be compacted in order to achieve the specified density. The PBL modified asphalt mixtures attained lower CEI and higher WI compared to M5000 modified asphalt mixture.

- In boiling water test and static water immersion test, the modified asphalt mixtures shows that more than $95 \%$ of the aggregate particle remain coated with asphalt binder in comparison to the control sample. The degree of coating for control sample is less than $95 \%$.

- From the Marshall stability test, it is proven that all modified asphalt mixtures exhibit higher stiffness. Which shows that modified asphalt mixture has greater resistance towards shear stress and permanent deformation. The M 1.0\% sample has the highest stiffness value.

- According to the SCB test, asphalt mixtures integrating adhesion promoters has higher resistance against fracture compared to the control sample. The incorporation of adhesion promoter significantly enhanced the asphalt-aggregate interface which leads to better resisatnce against fracture.

- From the ITS test, it can be deduced that the control specimen has the lowest indirect tensile strength ratio (ITSR) compared to the modified asphalt mixtures. While the M5000 modified asphalt mixtures demonstrated better resistance against moisture damage and stripping compared to PBL adhesion promoter.

\section{ACKNOWLEDGMENT}

The authors would like to acknowledge the partial financial support provided by the National Natural Science Foundation of China (NSFC) via the Research Fund for the international Young Scientist (Grant No. 51750110491), and the 
Department of Higher Education, Ministry of Education through the Fundamental Research Grant Scheme (203/PAWAM/6071358). The authors appreciate the cooperation given by the supplier of an adhesion promoter (Ingevity Ltd.) for providing us with the material and the required information. Also, thanks to all the technical staff of the Highway Engineering Laboratory, Universiti Sains Malaysia (USM) for continuous supports and helps.

\section{REFERENCES}

1. Kakar, M. R., Hamzah, M. O., \& Valentin, J. (2015). A review on moisture damages of hot and warm mix asphalt and related investigations. Journal of Cleaner Production, 99, 39-58. doi:10.1016/j.jclepro.2015.03.028

2. Al-Qadi, I. L., Abuawad, I. M., Dhasmana, H., \& Coenen, A. R. (2014). Effects of Various Asphalt Binder Additives/Modifiers on Moisture-Susceptible Asphaltic Mixtures. Research Report FHWA-ICT-14-004 A Report of the Findings of ICT-R27-078 Effects of Various Asphalt Binder Additives/Modifiers on Moisture-Susceptible Asphaltic Mixtures Illinois, 2014(1), 96-106. doi:10.4028/www.scientific.net/AMM.99-100.955

3. Behiry, A. E. A. E. M. (2013). Laboratory evaluation of resistance to moisture damage in asphalt mixtures. Ain Shams Engineering Journal, 4(3), 351-363. doi:10.1016/j.asej.2012.10.009

4. Sebaaly, P. E., Hajj, E. Y., Sathanathan, T., \& Shivakolunthar, S. (2015). A comprehensive evaluation of moisture damage of asphalt concrete mixtures. International Journal of Pavement Engineering, 8436 (September), 1-14. doi:10.1080/10298436.2015.1065404

5. Bhasin, A., Masad, E., Little, D., \& Lytton, R. (2006). Limits on Adhesive Bond Energy for Improved Resistance of Hot-Mix Asphalt to Moisture Damage. Transportation Research Record, 1970(1), 3-13. doi:10.3141/1970-03

6. Lytton, R. L., Masad, E. A., Zollinger, C., Bulut, R., \& Little, D. (2005). Measurements of Surface Energy and Its Relationship to Moisture Damage, (2), 172. Retrieved from https://static.tti.tamu.edu/tti.tamu.edu/documents/0-4524-2.pdf

7. Abuawad, I. M. A., Al-Qadi, I. L., \& Trepanier, J. S. (2015). Mitigation of moisture damage in asphalt concrete: Testing techniques and additives/modifiers effectiveness. Construction and Building Materials, 84, 437-443. doi:10.1016/j.conbuildmat.2015.03.001

8. Little, D. N., Allen, D. H., \& Bhasin, A. (2018). Asphalt Binders. Modeling and Design of Flexible Pavements and Materials. doi:10.1007/978-3-319-58443-0_2

9. Mohd Hasan, M. R., Hamzah, M. O., \& Teh, S. Y. (2017). Performance characterizations of asphalt binders and mixtures incorporating silane additive ZycoTherm. AIP Conference Proceedings (Vol. 1892). doi:10.1063/1.5005731

10. Dessouky, S., \& Diaz, M. (2016). Evaluation of Asphalt Mixes Workability and Compactability Using Laboratory and Accelerated Field Testing BT - Proceedings of the TMS Middle East Mediterranean Materials Congress on Energy and Infrastructure Systems (MEMA 2015). In I. Karaman, R. Arróyave, \& E. Masad (Eds.) (pp. 77-86). Cham: Springer International Publishing.

11. ASTM (2012). ASTM D3625: Standard Practice for Effect of Water on Bituminous-Coated Aggregate Using Boiling Water, ASTM International, West Conshohocken, PA.

12. BSI (2012). BS EN 12697-11: Bituminous mixtures - Test Methods for Hot Mix Asphalt - Part 11: Determination of The Affinity between Aggregate and Bitumen, British Standards Institution (BSI), London, United Kingdom.

13. ASTM (2006). ASTM D6927-06: Standard Test Method for Marshall Stability and Flow of Bituminous Mixtures, ASTM International, West Conshohocken, PA.

14. AASHTO (2018). AASHTO TP 124: Standard Method of Test for Determining the Fracture Potential of Asphalt Mixtures Using the Flexibility Index Test (FIT). American Association of State and Highway Transportation Officials, Washington D. C.

15. Somé, C., Fredj, M., Nguyen, M. L., Feeser, A., \& Pavoine, A. (2017). Multi-parametric characterization of mode I fracture toughness of asphalt concrete: Influence of void and RA contents, binder and aggregate types. International Journal of Pavement Research and Technology (Vol. 11). doi:10.1016/j.ijprt.2017.10.004

16. AASHTO (2014). AASHTO T 283: Standard Method of Test for Resistance of Compacted Asphalt Mixtures to Moisture-Induced
Damage. American Association of State and Highway Transportation Officials, Washington D. C

17. Zhu, C., Xu, G., Zhang, H., Xiao, F., Amirkhanian, S., \& Wu, C. (2018). Influence of different anti-stripping agents on the rheological properties of asphalt binder at high temperature. Construction and Building Materials, 164, doi:10.1016/j.conbuildmat.2017.12.236

18. Liu, Y., Apeagyei, A., Ahmad, N., Grenfell, J., \& Airey, G. (2014) Examination of moisture sensitivity of aggregate-bitumen bonding strength using loose asphalt mixture and physico-chemical surface energy property tests. International Journal of Pavement Engineering. Taylor \& Francis. doi:10.1080/10298436.2013.855312

19. Kok, B. V., Kuloglu, N., Bağlayıcıların, F., Asfalt, S., Mekanik, K., \& Etkisi, Ö. (2007). The Effects of Different Binders on Mechanical Properties of Hot Mix Asphalt. International Journal of Science \& Technology, 2(1), 41-48.

20. Akzo Nobel N.V. (2019). Adhesion Promoters for Bitumen. Retrieved from

https://e-asphalt.com/wp-content/uploads/2019/04/akzoadhesion.p df

21. South Carolina Department of Transportation. (2018). Laboratory Performance of Liquid Anti-Stripping Agents in Asphalt Mixtures used in South Carolina

22. Nazirizad, M., Kavussi, A., \& Abdi, A. (2015). Evaluation of the effects of anti-stripping agents on the performance of asphalt mixtures. Construction and Building Materials, 84, 348-353. doi:https://doi.org/10.1016/j.conbuildmat.2015.03.024

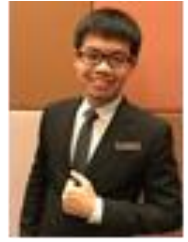

\section{AUTHORS PROFILE}

Mr. Nge Jia Sheng is an undergraduate student at the School of Civil Engineering, Universiti Sains Malaysia (Engineering Campus). He had done his Final Year Project (FYP) under the research area of pavement material. His FYP is focusing on adhesion promoters for better bonding mechanism.

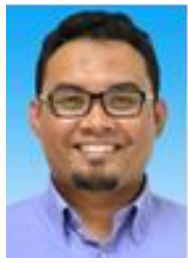

Dr. Mohd Rosli Mohd Hasan is currently an academic staff in highway engineering at the School of Civil Engineering, Universiti Sains Malaysia (Engineering Campus). He received a doctoral degree in civil engineering (transportation materials) from Michigan Technological University. He has published at least 60 papers in several local and international journals and conference proceedings. His research focuses on sustainable transportation materials and asphalt technology. He has been involved in several professional organizations, including Road Engineering Association Malaysia (REAM), Road Engineering Association of Asia and Australasia (REAAA), Malaysia Pavement Society (MYPAVES), and Transportation Science Society of Malaysia (TSSM).

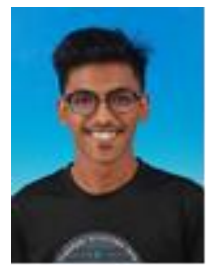

Mr. Sharvin Poovaneshvaran is currently an MSc student at the School of Civil Engineering, Universit Sains Malaysia (Engineering Campus). He received his bachelor's degree at Universiti Sains Malaysia as well. His research area is focusing on asphalt technology utilizing rubberized material. $\mathrm{He}$ is currently actively being involved in journal publication.

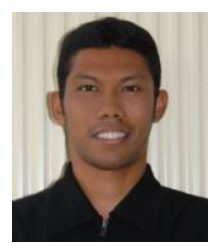

Assoc. Prof Dr. Ramadhansyah Putra Jaya is currently an academic staff at the Faculty of Civil Engineering Technology, Universiti Malaysia Pahang. He has published at least 200 papers in several local and international journals and conference proceedings. 
Assessments on the Performance of Asphalt Mixtures Prepared with Adhesion Promoters

Mr. Ali Huddin Ibrahim is currently appointed as a research officer at the School of Civil Engineering,

Universiti Sains Malaysia. He is an active researcher

on wide ranges of research area related to the Civil and

Environmental Engineering. 